tory care, and that one of the principal opportunities for this is in the detection and management of hypertension. ${ }^{6}$

The experts are, then, agreed; but what is happening in reality? A survey of practice records in north east Scotland last year showed that the rule of halves still applied, with only $34 \%$ of men over 20 years having a blood pressure recorded in their notes over a period of 10 years. ${ }^{7}$ Indeed, no evidence was found of any improvement in the practices over two successive five year periods. The position was similar to that shown in a study of inner London practices in 1974 by Heller and Rose, ${ }^{8}$ who also found very low standards of management of hypertension in hospitals, including teaching hospitals. ${ }^{9}$ Two more papers (pp 903, 906) show that the same lamentable approach is still apparent in London general practices, with two thirds of the adult population neglected in this way. Gross defects in management are shown, with $46 \%$ of patients in Haines's study beginning treatment after only a single reading and only three out of 84 having had urine tests. Both papers show that about a third of those who had begun to receive treatment were not continuing to have it. Particularly serious in its implications is the finding by Michael of no difference in the deficiencies between training and non-training practices.

What is to be done? It would be foolish to pretend that the task is easy. Some might claim that the management of patients with hypertension is beyond the scope of general practice altogether and should be the responsibility of hospitals. Even if it could be shown, however, that the quality of care in hospitals is better for individual patients this is largely a matter of organisation and staffing rather than clinical acumen or a personal sense of responsibility. Furthermore, the large numbers of patients needing treatment would certainly preclude a solution along these lines.

What is needed is a fundamental change in the structure of general practice. The traditional pattern is based on episodic consultations for symptomatic complaints and has no tradition of follow up. Even doctors who take pride in their achievements are often chastened by audit of their own results in chronic diseases. The primitive state of the records system inherited unmodified from the days of Lloyd George makes systematic collection of data difficult. Simple registers of hypertensive patients on card index file or on the fashionable microcomputers are a vital necessity for every practice if patients' treatment is to be maintained.

An important development which may provide the seeds of a solution is the training of nurses in the management of hypertension. In the Medical Research Council trial of treatment of mild to moderate hypertension nurses were trained to screen and treat patients in the study according to a structured protocol and achieved a high rate of compliance and satisfactory reductions in blood pressure. ${ }^{10}$ The British Hypertension Society is now running training courses for nurses. These should be supported by the Department of Health and Social Security, and nurses should be encouraged to attend by full reimbursement of expenses. Doctors must also learn the art of delegation of tasks, traditionally theirs, which they are not necessarily in a position to accomplish unaided. Despite allowances for two ancillary helpers for each principal in general practice the mean take up rate is only 1.0 so there is plenty of slack (DHSS, personal communication, 1984).

Finally, those in charge of vocational training face a serious challenge. Training practices (at least) should be reviewed by periodic audit of their management of hypertension. Some doctors may perceive this proposal as threatening, but only by facing up realistically to the problems as they are and not pretending things are better than they look will we make the really major changes that are needed. Then-in the context of hypertension-we might be more profitably employed in the next decade than in the last.

General Practitioner,

JOHN COOPE

Bollington,

Near Macclesfield SK10 5JL

1 Veterans Administration Cooperative Study Group on Antihypertensive Agents. Effects of treatment on morbidity in hypertension. Results in patients with diastolic blood pressures averaging 115 through $129 \mathrm{~mm}$ Hg. F $A M A$ 1967;202:1028-34.

2 Veterans Administration Cooperative Study Group on Antihypertensive Agents. Effects of treatment on morbidity in hypertension. II. Results in patients with diastolic blood pressure averaging 90 through $114 \mathrm{~mm}$ Hg. FAMA 1970;213:1143-52.

2a Management Committee. The Australian therapeutic trial in mild hypertension. Lancet 1980;i:1261-7.

${ }^{3}$ Hart JT. Semicontinuous screening of a whole community for hypertension. Lancet 1970 ;ii :223-6.

${ }^{4}$ Hart JT. The management of high blood pressure in general practice. I $R$ Coll Gen Pract 1975;25:160-92.

${ }^{5}$ Coope JR. Management of hypertension in general practice. In: $A B C$ of hypertension. London: British Medical Association, 1981:42-4.

${ }^{6}$ Royal College of General Practitioners. Health and prevention in primary care. London: Royal College of General Practitioners, 1981.

' Ritchie LD, Currie AM. Blood pressure recording by general practitioners in north-east Scotland. Br Med $\mathcal{F} 1983 ; 286: 107-9$.

${ }^{8}$ Heller RF, Rose G. Current management of hypertension in general practice. $B r$ Med $\mathcal{F}$ 1977; : :1442-4.

${ }^{9}$ Heller RF, Rose G. Current management of hypertension in hospital. Br Med F 1977;i:1441-2.

${ }^{10}$ Barnes GR. Nurse-run hypertension clinics. $\mathcal{F}$ R Coll Gen Pract 1983;33: 820-1.

\section{Natural or unnatural foods?}

Belief seems to be growing - and not just among food faddists - that in some way natural foods are to be preferred. The growing numbers of health food shops selling a wide range of natural foods is a testimony to this belief. "Natural" has (like so many words) been devalued by the advertising copywriter, and the Food Standards Committee recommended in 1966 that "natural" (as applied to food) should signify "raw, unmixed, unadulterated, and unprocessed."1

In a wider sense, however, all foods are natural, in that they are derived from plants, fungi, or animals, for the truly synthetic food of science fiction is a long way off. Nevertheless, it has been argued that the application of agricultural techniques is unnatural, that the current plant varieties and breeds of animals are the products of man's manipulation of nature, and that the closer food producers return to primitive sources and methods the more "natural"-and so the healthier-their products will be. It would be facile to dismiss this belief in the superiority of natural foods as merely a reaction to the complexities of modern living and a desire to return to the good old days. The belief in natural foods seems to rest on several tenets which need to be examined and assessed.

Firstly, natural foods are thought to be free from undesirable contamination from agrochemicals (artificial fertilisers, insecticides, pesticides, and the like). The individual consumer cannot easily assess whether or not "natural" foods are free from contaminants, but past abuses that have been given wide publicity have served to strengthen the hands of the regulating bodies. Properly used, agrochemicals do not present any real hazards, and they offer real advantages in increased yield and freedom from disease in many crops. In Britain regular surveillance of residues in foods is carried out by the Ministry of Agriculture, Fisheries and Food, and the reports of these studies are published and freely available. ${ }^{2}$ 
Secondly, "natural" foods are-or should be-free from food additives and preservatives; again, these substances have generated a considerable undercurrent of concern. All food additives are subject to close scrutiny by the ministry's Food Additives and Contaminants Committee (now the Food Advisory Committee) and have to meet two essential criteria: are they necessary and are they safe ? Most additives are used to control the stability or the sensory qualities of the foods in which they are used.$^{3}$ In part, their widespread use is a reflection of the need of the food processor to produce a consistent product from biologically variable starting materials. The safety testing of food additives is expensive, and few would regard the present procedures as wholly satisfactory. ${ }^{3}$ The effects of a lifetime's consumption in man are difficult to assess, and the procedures only rarely identify components that produce food intolerance and allergic reactions. Certainly many natural foods are allergenic, but in these cases the affected person can avoid the food in question. With processed foods not only is it more difficult for the victim of a reaction to identify the component responsible but also someone who knows he is sensitive to an ingredient (natural or artificial) often cannot easily find out whether or not a food contains the substance in question. Clearly better ways need to be found for identifying those foods which contain ingredients for which there is evidence of allergenic properties.

Thirdly, those who favour natural foods seem to believe that processing is in itself deleterious. Such a view discounts the fact that many foods are virtually inedible until they have been processed-for example, wheat grains. In other cases food processing is no more than converting domestic procedures, carried out on a small and uncontrolled scale in the kitchen, into a large scale, controlled process in the factory. The losses of nutrients that occur on the domestic scale are frequently equal to or greater than those in the factory. ${ }^{4} \mathrm{~A}$ wide range of processing operations of this kind have been used in preparing foods for a long time without any real evidence that harm results. In Canada it has been proposed that processing operations should be divided into two categories, ${ }^{5}$ and that those that are regarded as producing unimportant changes (which include a wide range of operations analogous to domestic cooking and many others, such as blanching, pasteurisation, dehydration, and even irradiation with gamma rays) should be allowed in the context of "natural."

More complex processing methods imply refining or "reforming"-taking the components of foods and processing them to produce novel or simulated structures. These processes may affect the amounts of minerals and vitamins of the food products, since losses of labile vitamins such as vitamin C, folate, and thiamine and of trace elements do occur. ${ }^{4}$ The nutritional importance of these changes in relation to the diet as a whole remains to be assessed, but it may be important as these products become established and form a greater proportion of the average man's diet. There is evidence that the physiologically beneficial properties of dietary fibre ${ }^{6}$ depend on its presence in its natural state and that disruption of cell wall structures, ${ }^{7}$ reduction of particle size,${ }^{8}$ and even relatively mild drying ${ }^{9}$ may alter these properties unfavourably.

Many composite processed foods also incorporate substantial amounts of fat and sugar in a form that cannot be readily recognised by the consumer. Anyone who wishes to regulate his energy intake would benefit from clear labelling or from efforts to produce processed foods with reduced amounts of these components ${ }^{10}$ - which both add to the energy value of the food and reduce its nutrient density.
The proponents of natural foods often argue that they taste better. This proposition is very difficult to test; certainly natural foods have more variable sensory qualities, ranging from excellent to poor. The food manufacturer tends to aim at a uniform middle of the road quality that will neither offend the majority nor enrapture the gourmet; consumers, too, seem to expect consistency of sensory quality in processed foods. Many such foods have no "natural" equivalent so that no real tests can be applied, and in some cases nominally analogous processed and natural (fresh) products are, in fact, quite different foods.

No evidence has been produced to show that modern plant and animal husbandry and food processing produce foods that are unsafe to eat. Indeed, the contrary is true, especially in relation to microbiological safety. Both the agricultural techniques that have been developed to produce a regular and consistent supply of safe, palatable food, and the processing methods needed to conserve it are essential to our modern, largely urban society. ${ }^{11}$ Nevertheless, there are nutritional advantages in the consumption of fruits, vegetables, and high extraction cereal foods in a fresh or minimally processed state, ${ }^{12}$ and natural foods in this category merit promotion. Choosing "natural" or primary foodstuffs does provide the consumer with a greater element of control over the food he ingests; and, though some of the benefits of this control may be illusory, many consumers find this self reliance more satisfying. A price must, however, be paid: any widespread return to older methods of plant and animal husbandry and the rejection of the hygienic standards and skills of the food technologist would have important economic and social implications. If some of the changes in the British diet that are considered desirable on health grounds take place ${ }^{13}$ there will be an increased consumption of fresh foods and a reduced consumption of some processed foods as they are formulated at present. Producing a "new generation" of processed foods will pose a formidable challenge to the food industry-but one which it should be capable of meeting.

D A T SOUThgate

Head,

Nutrition and Food Quality Division,

Food Research Institute,

Norwich NR4 7UA

${ }^{1}$ Ministry of Agriculture, Fisheries and Food. Food Standards Committee. Report on claims and misleading descriptions. London: HMSO, 1966.

2 Ministry of Agriculture, Fisheries and Food. Steering Group on Food Surveillance. The surveillance of food contamination in the United Kingdom. London: HMSO, 1978.

${ }^{3}$ British Nutrition Foundation. Why additives? The safety of foods. London: Forbes Publication, 1977.

4 Bender AE. Food processing and nutrition. New York: Academic Press, 1978.

${ }^{5}$ Department of Consumer and Corporate Affairs, Canada. Draft guidelines to restrict the use of the term "natural" in describing food products. Ottawa: Information Department, DCCA, 1983.

${ }^{5}$ Royal College of Physicians. Medical aspects of dietary fibre. A report from the Royal College of Physicians of London. Tunbridge Wells: Pitman Medical, 1980.

${ }^{7}$ Haber GB, Heaton KW, Murphy D, Burroughs LF. Depletion and disruption of dietary fibre. Effects on satiety, plasma-glucose, and seruminsulin. Lancet 1977 ;ii :679-82.

- Brodribb AJM, Groves C. Effects of bran particle size on stool weight. Gut 1978;19:60-3.

${ }^{9}$ Robertson JA, Eastwood MA. An investigation of the experimental conditions which could affect the water-holding capacity of dietary fibre. I Sci Food Agric 1981 ;32:819-25.

${ }^{10}$ Royal College of Physicians. Obesity. $\mathcal{J} R$ Coll Physicians Lond 1983;17: 5-65.

"Anonymous. Food technology in the 1980s. British Nutrition Foundation Bulletin 1975;3:20-6.

1:2 Department of Health and Social Security. Prevention and health. Eating for health. London: HMSO, 1978.

${ }^{13}$ National Advisory Committee on Nutrition Education. Proposals for nutritional guidelines for health education in Britain. Lancet 1983;ii : $719-21,782-5,835-7,902-5$ 